\title{
Natural surfactants towards a more sustainable fluorine chemistry
}

\author{
V. Dichiarante, (iD *a R. Milani iD ${ }^{b}$ and P. Metrangolo (iD *a,b,c
}

Fluorinated materials play an essential role in modern industry and technology, and their importance is expected to grow even more in the near future. Unfortunately, their practical application often requires dispersion by means of fluorinated surfactants, which raised huge environmental and toxicity concerns due to their long-lasting persistence in the environment and high tendency to accumulate in animals and humans. A greener and more sustainable strategy towards the replacement of synthetic fluorosurfactants is offered by the use of amphiphiles of biological origin. Among them, phospholipids have been the most widely exploited as emulsifiers of fluorous compounds. Some interesting examples were also reported using amphiphilic proteins, in particular fungal hydrophobins, as biosurfactants and coating agents for fluorinated substrates. This perspective offers an overview of the main natural surfactants currently used in fluorine chemistry, focusing in particular on two main application areas: (i) fluorous oil-in-water emulsions and gas microbubbles for biomedical imaging and drug delivery, and (ii) coating and functionalization of solid fluorinated surfaces.

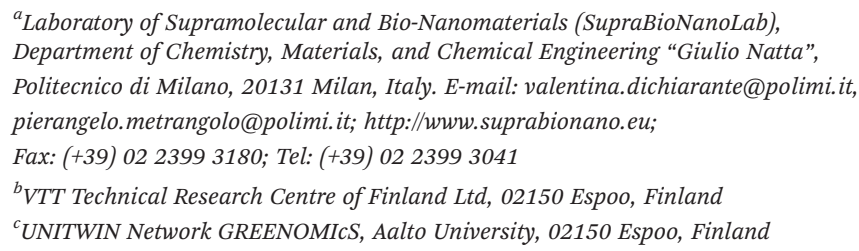

This is the accepted version of V. Dichiarante, R. Milani, P. Metrangolo, "Natural surfactants towards a more sustainable fluorine chemistry", Green Chem., 2018, 20, 13-27.

The final publication is available at: https://doi.org/10.1039/C7GC03081A 


\section{Introduction}

Fluorine chemistry has become essential for many aspects of modern day life, so that related industry and technology are expected to further increase in the next years with an esti-mated annual growth rate comprised between 2 and $4 \%$ for different specialties. ${ }^{1}$ Indeed, several fluorocompounds -including polymers, surfactants and surface coating agents -

are widely exploited to enhance the functionality and durability of aircrafts, automobiles, buildings and electronics, thanks to their unmatched thermal and chemical stabilities, unique dielectric properties, and water and oil repellency. ${ }^{2}$ Fluoropolymers, for example, find widespread use in automotive applications thanks to their exceptional resistance to fuels, lubricants, high temperatures and aggressive chemicals, as well as to their low coefficients of friction and non-wetting surfaces. ${ }^{3}$ Furthermore, these polymers can greatly enhance the properties of coatings used in modern industrial, household, and construction products, particularly in terms of chemical, UV, moisture, and dirt resistance. Fluorinated coatings find applications also in electronics, optics, polishes, inks, textiles, and adhesives. ${ }^{1}$ One of the most common classes of fluorochemicals is that of fluorinated surfactants (F-surfactants), amphiphilic molecules containing both a hydrophilic and a fluorophilic moiety. ${ }^{4}$ These surface-active compounds allow the stabilization of various colloidal systems, including different types of emulsions and vesicles, and improvement of the solubility of poorly water-soluble materials thanks to their excellent performance as emulsifying, dispersing, foaming, wetting, cleansing, and phase separating agents. For these reasons, fluorosurfactants find several applications in polymer, food, cosmetic and pharmaceutical industries. Among them, perfluorooctanoic acid (PFOA) and perfluorooctanesulfonic acid (PFOS) have been for years the most extensively produced and used (Chart 1).

Unfortunately, a series of environmental and toxicity studies raised huge concern about their use, since both PFOA and PFOS were shown to degrade slowly under environmental conditions. ${ }^{5}$ Due to their persistence in the environment, these man-made perfluorinated derivatives tend to accumulate in cells and were found in animal and human tissues almost everywhere. A series of toxicity studies performed on animals suggested that long-chain linear perfluoroalkyl derivatives con-
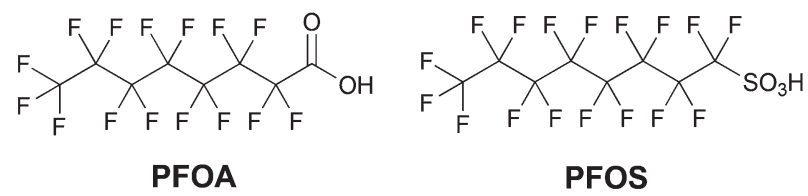

Chart 1 Chemical structures of perfluorooctanoic acid (PFOA) and perfluorooctanesulfonic acid (PFOS).

taining more than six $\mathrm{CF}_{n}$ units (like PFOA and PFOS) may induce serious toxic and endocrine disrupting effects. ${ }^{6}$ Due to their long-lasting persistence, worldwide distribution, high tendency to bioaccumulate, and suspected toxicity, PFOS and its salts were thus listed as persistent organic pollutants under the Stockholm Convention. ${ }^{7}$ Furthermore, in 2006 the US Environmental Protection Agency (EPA), in collaboration with the eight major companies in the fluorochemical industry, launched a Stewardship Program to commit to working towards the elimination of PFOA and its derivatives from emissions and products by $2015 .^{8}$ Given the increasing need for fluorinated products in everyday life and industry on the one hand, and their potential for danger for the environment and animal species on the other, a key target is thus to reach a compromise between these two crucial issues, establishing a route towards a more sustainable fluorine chemistry. ${ }^{9}$ Several world-leading companies (e.g., Daikin, DuPont, 3M/Dyneon and Solvay Solexis) have met the EPA program's intermediate goal of a 95\% reduction in global emissions and product content by 2010 , and are actively searching for more sustainable F-surfactants.

It would be highly desirable, for example, to design environmentally sustainable fluoropolymers that are able to form polymeric films or coatings from an aqueous phase without the need for fluorinated dispersing agents. Unfortunately, their very low water solubility and surface tension require the use of surfactants or other forms of surface modification. The use of F-surfactants to stabilize colloidal dispersions is still widespread, in spite of the related significant environmental concerns. The first, more immediate, approach adopted to face concerns over the environmental impact of long-chain perfluoroalkyl acids (PFAAs) was their substitution with alternative, but structurally similar, fluorinated substances. The main companies active in the fields of the fluoropolymer industry and textile treatment developed several alternative compounds having shorter perfluorinated groups (typically shifting from $\mathrm{C}_{8}$ to $\mathrm{C}_{4}$ perfluorinated chains) or "weak" degradable points, like methylene or ether groups. Unfortunately, such fluorinated alternatives, particularly short-chain PFAAs and perfluoroether-carboxylic and sulfonic acids, are less performing from a technical point of view, possess high environmental stability and mobility, and may still have a contamination potential. ${ }^{5}$ Global Warming Potential (GWP) values relative to $\mathrm{CO}_{2}$ for $\mathrm{C}_{3}$ and $\mathrm{C}_{4}$ perfluoroalkanes, for example, are quite similar to those of longer-chain PFCs, reaching values higher than 10000 on a 500-year time horizon. ${ }^{10}$ In addition to that, some of these fluorinated alternatives were identified as possibly 
toxic for animals and humans, although a deep knowledge about the real risks posed by them is currently lacking. ${ }^{11}$

A greener, effective, and long-term more sustainable strategy towards the elimination of chemically synthesized F-surfactants is their replacement with natural amphiphilic compounds produced by a variety of microorganisms, such as bacteria, yeasts, and fungi. ${ }^{12,13}$ Surfactants of biological origin show unique properties in terms of low toxicity, specific activity even under extreme conditions, and biodegradability. They include low molecular weight compounds (like lipopeptides or glycolipids) and high molecular weight polymers (e.g., proteins). Up to now, phospholipids have been the most extensively studied biosurfactants for applications in fluorine chemistry. Many research efforts focused in particular on the use of egg yolk phospholipids (EYP), a natural mixture of phospholipids derived from chicken hen's eggs composed mainly of phosphatidylcholine and phosphatidylethanolamine plus a significant percentage of unsaturated acyl chain species. Several naturally occurring proteins are already used as foaming agents and surfactants in food processing, cosmetics and pharmaceuticals. In the biomedical field, biocompatible and microbe-resistant protein foams would be highly advantageous for tissue regeneration, directed cell growth, and coating of surgical implants. Most of these applications are strictly related to fluorine chemistry. Indeed, fluorine plays a paramount role in medicinal chemistry and drug design not only as evidenced in the fast-growing number of fluorinated drugs (representing about $60 \%$ of the top-selling pharmaceuticals), but also in the development of better health care products, such as bioinert and non-fouling surgical implants, catheters, stents and needles. ${ }^{14}$ In the past years, a significant number of studies appeared in the literature that exploited the amphiphilic properties of hydrophobins (HFBs), a family of low molecular weight (7-15 kDa), highly surface active and film-forming proteins produced by filamentous fungi. ${ }^{15}$ HFBs usually comprise about 100 amino acids and always contain four disulfide bridges in the protein core, which confer remarkable stability to their structure. Their unique amphiphilic behaviour is due to the presence on their surface of a discrete portion fully composed of amino acids with hydrophobic side chains, the so-called 'hydrophobic patch'. ${ }^{16}$ This structural feature drives the spontaneous self-assembly of HFBs into strong and elastic films at both air/water and hydrophobic/hydrophilic interfaces, promoting their successful exploitation as novel biosurfactants, coating and adhesion agents, as well as surface modifiers. ${ }^{17,18}$ HFBs are classified into two groups, according to the different clustering modes of hydrophobic and hydrophilic residues in their structure. Class I HFBs (e.g., SC3, Vmh2, and HGFI) tend to form poorly watersoluble aggregates, whereas Class II HFBs like HFBI and HFBII self-assemble into structures which are more soluble in aqueous media. At interfaces, Class II HFBs form significantly elastic monolayers, while Class I proteins usually lead to multilayers. ${ }^{19,20}$ The addition of low concentrations of hydrophobins to food foams, for example, is known to increase their stability. ${ }^{21}$ Upon assembly at aqueous/fluorous interfaces, hydrophobins rapidly reduce the interface tension by typically $15-20 \mathrm{mN} \mathrm{m}^{-1}$. This feature, together with the peculiar ability of HFBs to form strong interfacial films, makes them potentially more advantageous than other biosurfactants for solubilizing fluorous phases in aqueous environments.

Here we will present an overview of the natural surfactants most commonly used for filming or dispersing fluorinated substrates. Papers reported in the literature will be classified into two main areas, according to the type of pursued application. First, we will focus on the stabilization of fluorous oilin-water $(\mathrm{o} / \mathrm{w})$ emulsions and gas microbubbles for biomedical purposes and drug delivery. In the following section, we will highlight examples of coating, modification, and functionalization of solid fluorinated surfaces by means of biosurfactants and their derivatives.

\section{Biomedical imaging and drug delivery applications}

Fluorocarbon-based formulations have been employed in injectable microbubble contrast agents and emulsions for oxygen delivery, drug delivery, targeted therapeutics, and molecular imaging applications. Their actual effectiveness and safety depend on several factors, such as easy availability, low cost, lack of toxicity, easy handling and storage, stability over time, and compatibility with all blood types.

\subsection{Echogenic gas microbubbles for ultrasound imaging}

Colloidal bubbles (commonly called 'microbubbles') are highly effective contrast agents for ultrasound diagnostics, especially for the detection and treatment of cardiovascular diseases. All the commercially available microbubbles have a diameter usually smaller than $10 \mu \mathrm{m}$ and contain a fluorinated gas inner core, which provides osmotic stabilization and contributes to interfacial tension reduction. Thanks to their low solubility in aqueous media (if compared to air, oxygen or nitrogen), fluorinated gases dissolve more slowly, and thus afford longer lived microbubbles. ${ }^{22}$ Their gas core can resonate when exposed to ultrasounds, making them useful contrast agents for ultrasound (molecular) imaging, or targeted drug and gene delivery. Obviously gas bubbles of this size are not soluble in aqueous media, due to surface tension effects. For this reason they require a stabilizing shell, usually made of one or more surfactants (including lipids, proteins, and polymers). The ultrasonic behavior of microbubbles depends on their size and on the type of encapsulated gas, but also on the composition of their outer shell. In general, a more elastic shell is more easily compressed by ultrasounds and will resonate better. On the other hand, excessively rigid shells are more prone to rupture if subjected to insonication. ${ }^{23}$ Lipids provide highly echogenic bubbles with $3 \mathrm{~nm}$ average thickness shells, which rapidly break in ultrasound fields, but can reseal afterwards. Lipid-based microbubbles originate from the self-assembly of phospholipids at the gas-water interface into a monolayer held together by weak hydrophobic and van der Waals inter- 
actions. This thin monolayer makes them highly responsive to ultrasounds, which can be beneficial for both molecular imaging and drug or gene delivery. ${ }^{24}$ Protein shells usually have 15-20 nm thickness. The resulting microbubbles are characterized by medium stability and high echogenicity, but are unable to reseal after rupture. These formulations commonly use albumin proteins. ${ }^{24}$ Some papers, however, showed that other proteins, such as lysozyme and avidin, may work as well, at least with air bubble formulations. ${ }^{25,26}$ The incorporation of other bioactive proteins or plasmid DNA into albumin-based microbubbles can potentially improve their functionality, and thus significantly boost their biomedical importance. $^{24}$ Both these families of amphiphilic biomolecules afford a much better echogenic performance than synthetic polymers, whose thicker shells (100-200 nm) are more resistant to compression and expansion, but do not reseal after rupture and tend to dampen ultrasonic waves, thus reducing echogenicity. ${ }^{24}$ Table 1 offers an overview of the currently approved, or in clinical trial, microbubble-based ultrasound contrast agents stabilized by natural surfactants, either polymeric (proteins) or molecular ones (phospholipids). Among protein-coated bubbles it is worth to mention Optison ${ }^{\circledR}$, an albumin-based formulation encapsulating perfluoropropane gas which was approved by the US FDA for contrast echocardiography. ${ }^{27}$ A higher number of lipid-shell microbubbles, such as Definity ${ }^{\circledR}$, Sonovue ${ }^{\circledR}$ and Sonazoid ${ }^{\circledR}$, were developed for biomedical imaging, thanks to their better performance. $^{28-30}$ This last one, in particular, is stabilized by an anionic phospholipid (phosphatidylserine) that accumulates in macrophages and is thus useful for liver imaging (Fig. 1).

Specific targeting agents were also added to the phospholipid layer, as in the case of BR-55®, which contains also a lipopeptide targeted to the receptor for vascular growth factor. ${ }^{32}$ DNA- and RNA-targeted cationic microbubbles for gene delivery were obtained by the incorporation of cationic lipids into the stabilizing shell, in order to establish electrostatic interactions with negatively charged nucleic acids. Furthermore, the incorporation of lipids bearing polyethyleneglycol (PEG) into the lipid shell prevents the binding of microbubbles to serum proteins and the subsequent shortening of their serum half-life. ${ }^{24}$

In the past years, great advances were achieved in both preparation procedures and investigation methods, allowing an improved control on microbubble formation, stability,

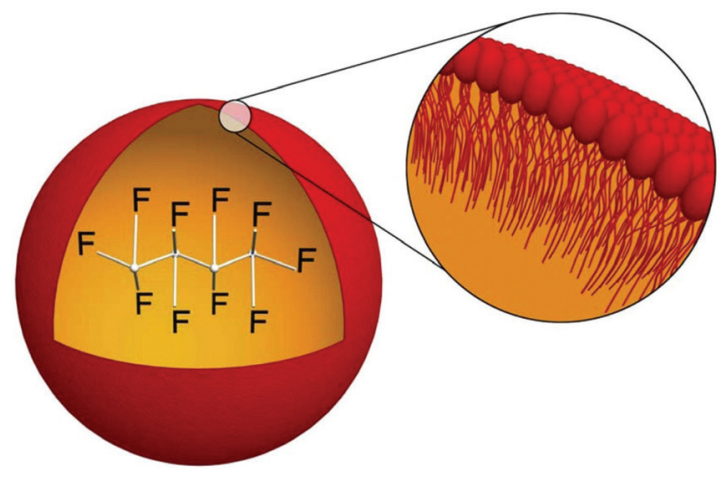

Fig. 1 Structure of a Sonazoid ${ }^{\circledR}$ microsphere, with the perfluorobutane core stabilized by a $2-3 \mathrm{~nm}$ thick monolayer of egg phosphatidylserine (reproduced from ref. 30 with permission from Elsevier).

structure and properties. ${ }^{33}$ Nguyen et al. studied the adsorption dynamics of a series of phosphatidylcholines at the interface between an aqueous lipid solution or dispersion, and air saturated with perfluorohexane gas, by means of bubble profile analysis tensiometry. ${ }^{34}$ With all the selected phospholipids (namely, the dioctanoyl-, dilauryl-, dimyristoyl-, and dipalmitoyl-substituted phosphatidylcholines), perfluorohexane had a strong effect on both their adsorption rate and equilibrium interfacial tension $\left(\gamma_{\mathrm{eq}}\right)$.

At all the concentrations investigated, $\gamma_{\text {eq }}$ values were significantly lower (up to $10 \mathrm{mN} \mathrm{m}^{-1}$ ) compared to those obtained using pure air as the gas phase. In addition to that, all the phospholipid adsorption rates at the interface were up to fivefold higher when perfluorohexane was present. Both the surface tension reduction and the adsorption rate increase confirmed the strong interaction between the perfluorinated gas and the lipid monolayer, forming a mixed interfacial layer where the fluorocarbon acts as a co-surfactant.

Interestingly, a similar effect was very recently observed also when using the hydrophobin HFBII as a shell component. ${ }^{35}$ Using perfluorohexane gas, size-controlled echogenic spherical microbubbles were obtained, which proved to be stable in mean diameter and size distribution for at least two months at $25{ }^{\circ} \mathrm{C}$. From a biomedical perspective this achievement shows the potential of HFBs as shell components in microbubblebased ultrasound imaging, and may be particularly relevant considering that both HFBII and gaseous perfluorohexane are expected to be biologically inert.

Table 1 Core and shell composition, and possible applications of the main fluorinated microbubble contrast agents for ultrasound imaging based on natural surfactants

\begin{tabular}{llll}
\hline Product & Gas core & Surfactant shell & Applications \\
\hline Optison & Perfluoropropane $\left(\mathrm{C}_{3} \mathrm{~F}_{8}\right)$ & Human serum albumin & Ultrasound imaging of endocardial borders \\
Definity & Perfluoropropane $\left(\mathrm{C}_{3} \mathrm{~F}_{8}\right)$ & Phospholipids & Echocardiography \\
Sonovue & Sulfur hexafluoride $\left(\mathrm{SF}_{6}\right)$ & Phospholipids & Imaging of blood vessels, breast, liver \\
Sonazoid & Perfluorobutane $\left(\mathrm{C}_{4} \mathrm{~F}_{10}\right)$ & Egg phosphatidylserine & Detection of breast and liver lesions \\
BR-14 & Perfluorobutane $\left(\mathrm{C}_{4} \mathrm{~F}_{10}\right)$ & Phospholipids & Transcranial harmonic imaging \\
BR-55 & Perfluorobutane $\left(\mathrm{C}_{4} \mathrm{~F}_{10}\right)$ & Phospholipids, VEGFR & 29 \\
& & & Early detection of human tumors
\end{tabular}


Recently, also nanoscale echogenic bubbles were developed as ultrasound contrast agents. Their smaller size allows them to extravasate from vessels to tissues, in contrast to microsized bubbles (MBs). However, further optimization and toxicity assessment are still required before clinical application. ${ }^{36}$

A small particle size is a basic requirement for ultrasound contrast agents to penetrate tumor blood vessel pores and allow targeted imaging and therapy. However, nanoscale-sized particles usually weaken the imaging ability of clinical diagnostic ultrasounds. In 2012, using a thin-film hydration-sonication method, Yin et al. prepared small lipid-coated perfluoropropane nanobubbles with in vitro ultrasound imaging performance similar to that of microbubbles. ${ }^{37}$ The phospholipids used in this paper included 1,2-dipalmitoyl-sn-glycero-3-phosphocholine (DPPC), 1,2-distearoyl-sn-glycero-3-phosphoethanolamine- $\mathrm{N}$-[biotinyl(polyethylene glycol)2000] (PEG2000-DSPE) and 1,2-dipalmitoyl-sn-glycero-3-phosphate (DPPA).

Liquid core nanodroplets containing condensed low boiling point PFCs (e.g.) stabilized by lipid shells were vaporized at clinically relevant acoustic energies and have been hypothesized as an alternative ultrasound contrast agent instead of gas-core agents. ${ }^{38}$ The targeted transthoracic acoustic activation of such intravenously infused nanodroplets was effective, resulting in echogenic and persistent microbubbles which provided the real-time visualization of perfusion defects.

Such phase-change contrast agents (PCCAs) behave as ultrasonically activatable nanoparticles (Fig. 2). ${ }^{39}$ They consist of liquid PFCs with extremely low boiling points such as perfluoro-propane and -butane, that can be subsequently vaporized with low acoustic energy. Polydisperse decafluorobutane and octafluoropropane microbubbles were formulated with a mixture of 1,2-distearoyl-sn-glycero-3-phosphocholine (DSPC) and DSPE-PEG2000 in a 9:1 molar ratio, and a total lipid concentration of $1.0 \mathrm{mg} \mathrm{ml}^{-1}$.

Sub-micron phase change contrast agents (PCCAs) composed of a perfluorocarbon liquid core can be activated into the gaseous state and form stable echogenic microbubbles for the contrast-enhanced ultrasound imaging of microvasculature, tumour microenvironment, and cancer cells. Lin et al. prepared PCCAs via the condensation of precursor lipid-coated perfluorobutane-filled MBs. The stabilizing shell was formed by 1,2-dipalmitoyl-sn-glycero-3-phosphocholine (DPPC) and

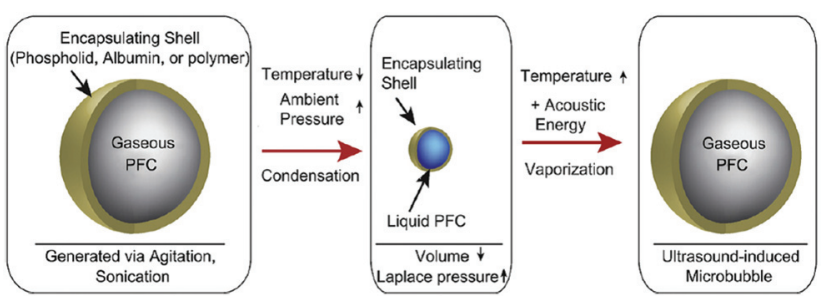

Fig. 2 Condensation and subsequent re-vaporization of gaseous perfluorocarbon microbubbles (reproduced from ref. 39 with permission from Elsevier). 1,2-dipalmitoyl-sn-glycero-3-phosphoethanolamine- $N$-[methoxy (polyethylene glycol)-2000] in 9:1 molar ratio. ${ }^{40}$ PCCAproduced ultrasound contrast enhancement after acoustic activation in a microchannel phantom (a $200 \mu \mathrm{m}$ cellulose tube mimicking microvessel confinement) was more than one order of magnitude lower than that in a free environment.

Unfortunately microbubbles have several drawbacks, including short half-lives (within a few minutes) and limited drug payload capacity. To improve cancer chemotherapy delivery and survival outcomes, long-circulating non-thermosensitive liposomes (NTSL) and low temperature sensitive liposomes (LTSL) were combined with high intensity focused ultrasound MBs. ${ }^{41}$ LTSLs (lipid composition: DPPC, MSPC, and DSPEmPEG2000 in 85.3:9.7:5.0 molar ratio) and NTSLs (DPPC, cholesterol, and DSPEmPEG2000 in 58.1:36.8:5.07 molar ratio) were prepared by the hydration of a lipid film, followed by extrusion. NTSLs and LTSLs containing doxorubicin (Dox) were co-loaded with perfluoropentane (PFP) using a one-step sonoporation method. PFP encapsulation improved Dox penetration in the tumor periphery and core, without any impact on the drug distribution in normal cells. ${ }^{41}$ Echogenic liposomes loaded with recombinant tissue-type plasminogen activator (rt-PA) and microbubbles that act as cavitation nuclei were also developed for ultrasound-mediated thrombolysis. ${ }^{42}$ Actually, rt-PA is the only FDA-approved thrombolytic for the treatment of acute ischemic stroke. Monodisperse rt-PA-loaded liposomes containing octafluorocyclobutane gas were prepared in a microfluidic flow-focusing polydimethylsiloxane device. The phospholipid mixture contained DSPC and 1,2-distearoylsn-glycero-3-phosphoethanolamine- $\mathrm{N}$-[amino(polyethylene glycol)-2000] (ammonium salt) (DSPE-PEG2000), plus 5\% v/v Pluronic F-127, which proved to be essential for particle stability. The lipid mixture and rt-PA were flowed in the outer and inner side channels of the chip, respectively, whereas gaseous PFC was delivered in the central flow channel. The longer acyl chains of DSPC are supposed to increase rigidity, and thus to allow a higher shell friction parameter, resulting in lower backscatter intensity and an increased threshold for nonlinear oscillations and microbubble rupture (if compared with commercial Definity®). ${ }^{42}$

\subsection{Perfluorocarbon-based oxygen carriers}

Perfluorocarbon (PFC)-based artificial oxygen carriers (also termed "blood substitutes" or "white blood") exploit the high solubility of respiratory gases (oxygen and carbon dioxide) in PFCs to restore oxygen transport to tissues. ${ }^{43}$ Obviously, since perfluorinated organic compounds are not soluble in water, the intravascular administration of these carriers requires their previous emulsification through coating by a thin surfactant layer. A proper biocompatible emulsifier for PFC emulsion development must fulfill two main tasks. First, it has to reduce the large interfacial tension between the highly hydrophobic PFC and the aqueous phase. The second target is to stabilize the resulting emulsion. Moreover, surfactants for intravascular use must be devoid of significant toxicity. The strength of a surfactant film is related to the hydrophobic interactions 
between the nonpolar units of its molecules. The stability of the emulsion also relies on cohesion at the PFC/water interface, which in turn depends on the solubility of the surfactant's hydrophilic moiety in the aqueous phase and of its hydrophobic moiety in the PFC phase (known as the hydrophilic/lipophilic balance of the surfactant). ${ }^{44}$

PFC emulsions reported so far have used essentially two surfactants, namely poloxamers and egg yolk phospholipids (EYP), as emulsifiers. As summarized in Table 2, first-generation emulsions used mainly synthetic Pluronics as emulsifiers, whereas second-generation products (e.g. Oxygent ${ }^{\circledR}$, Oxyfluor ${ }^{\circledR}$, and Oxycyte $\left.{ }^{\circledR}\right)$ mostly exploited natural phospholipids. ${ }^{45,46}$

EYP, in particular, has been used for more than fifty years for stabilizing intravenous injectable lipid emulsions for parenteral nutrition and, later on, for the preparation of liposomes. Among the many advantages provided by this surfactant mixture, we can cite a strong reduction of side effects, low PFC/water interfacial tension, excellent hydrophilic/lipophilic balance, better emulsion stability and lower Ostwald ripening rate compared to Pluronics. Furthermore, EYP cause no complement activation, and have longer intravascular half-lives. However, they are sensitive and oxidizable materials, and require specific expertise in handling and preparation. The oxidation of EYP in PFC emulsions can be minimized by the addition of minor amounts of metal chelators (e.g., EDTA) and antioxidants (e.g., $\alpha$-D-tocopherol). Other excipients - such as buffer salts - are frequently added to adjust osmolarity and $\mathrm{pH}^{43}$

Proteins have also been used in this context. Since the first physiologically compatible emulsion of perfluoro-2- $n$-butyltetrahydrofuran (FX-80) with bovine serum albumin was reported by Sloviter and Kamimoto, several efforts have been directed towards the improvement of emulsion stability. ${ }^{47}$

Despite the outstanding gas dissolving ability and inertness of PFCs, injectable fluorocarbon-in-water emulsions for oxygen gas delivery are actually affected by low stability, and require stabilization against coarsening to maintain biocompatibility after intravenous administration. Control of emulsion particle size distribution upon storage is particularly critical in preserving the efficacy and tolerability of blood substitutes and other fluorocarbon-based parenterals. The presence of secondary dispersed components in EYP, such as a small percentage of long-chain triglycerides, was shown to improve adhesion between the surfactant and the dispersed fluorous phase through the formation of a three-phase emulsion. In such dispersion, the triglyceride formed a layer around the dispersed fluorocarbon, and thereby improved the adhesion of phospholipid surfactants to the dispersed fluorinated phase. ${ }^{48}$

\section{3. ${ }^{19} \mathrm{~F}$ magnetic resonance imaging and related application}

Although most of the PFCs applied as imaging contrast agents were gaseous, in the past years many research efforts focused on less toxic liquid perfluorocarbons ${ }^{49}$ as possible dual-modal contrast agents for both ${ }^{19} \mathrm{~F}$ magnetic resonance imaging $\left({ }^{19} \mathrm{~F} \mathrm{MRI}\right)$ and ultrasonography. ${ }^{50}$ Due to the lack of a ${ }^{19} \mathrm{~F}$ endogenous background signal in vivo and the high magnetic resonance sensitivity of ${ }^{19} \mathrm{~F}$ atoms, the high fluorine content of liquid perfluorocarbons surely make them ideal tracers for MR imaging. Again, oil-in-water nanoemulsions were the most widely investigated tools to disperse PFCs in water for ${ }^{19} \mathrm{~F}$ MRI applications. The stabilization of PFC nanodroplets in aqueous media for in vivo applications was achieved by means of both synthetic surfactants, usually Pluronics, and natural emulsifiers, such as natural phospholipids from egg yolks, soybean, etc. (e.g., lecithin).

Similar to the case of microbubble dispersions, suitable emulsifiers for ${ }^{19} \mathrm{~F}$ MR imaging and cell labeling must be nontoxic, chemically stable, and able to decrease the high interfacial tension of perfluorocarbons in water. Natural phospholipids afforded better emulsion stability and fewer side effects than Pluronics, with EYP appearing to be a very favorable choice. Surfactant-lipid co-mixtures were also often used, as in the case of safflower oil mixed with cholesterol and/or glycerin. ${ }^{51}$ In particular, hydrophobic safflower oil was often added to decrease the emulsions' Ostwald ripening, a molecular diffusion phenomenon leading to a gradual growth of larger particles at the expense of smaller ones. ${ }^{52}$ Table 3 presents an overview of currently reported examples of natural dispersing agents and additives used for ${ }^{19} \mathrm{~F}$ MRI formulations, which have been recently reviewed. ${ }^{51}$ Here, we would just briefly mention the aqueous dispersion of perfluorooctyl bromide (PFOB) stabilized by an EYP monolayer adsorbed at the o/w interface, which was the first one thoroughly investigated for biomedical applications as imaging and oxygencarrying formulation. Minor components present in the commercially available surfactant mixture were found to be necessary for the formation of stable dispersions, probably acting as phospholipid carriers from the bulk to the interface. ${ }^{73}$ Most of

Table 2 Selected examples of PFC-based emulsions developed as artificial blood substitutes

\begin{tabular}{|c|c|c|c|}
\hline Product & & PFC $(\% \mathrm{w} / \mathrm{v})$ & Surfactant(s) \\
\hline $1^{\text {st }}$ generation emulsions & Fluosol & $\begin{array}{l}\text { Perfluorodecalin (14\%) } \\
\text { Perfluorotripropylamine (6\%) }\end{array}$ & Pluronic F68, EYP, potassium oleate \\
\hline $2^{\text {nd }}$ generation emulsions & Oxygent & $\begin{array}{l}\text { Perfluorooctylbromide (58\%) } \\
\text { Perfluorodecylbromide }(2 \%)\end{array}$ & EYP \\
\hline & $\begin{array}{l}\text { Oxyfluor } \\
\text { Oxycyte }\end{array}$ & $\begin{array}{l}\text { Perfluoro-dichlorooctane }(78 \%) \\
\text { tert-Butyl-perfluorocyclohexane }(60 \%)\end{array}$ & $\begin{array}{l}\text { EYP, safflower oil } \\
\text { EYP }\end{array}$ \\
\hline Emulsions in progress ${ }^{46}$ & $\begin{array}{l}\text { Columbian emulsion } \\
\text { French emulsion }\end{array}$ & $\begin{array}{l}\text { Perfluorooctylbromide (58\%) } \\
\text { Perfluorooctylbromide }(90 \%)\end{array}$ & $\begin{array}{l}\text { Soybean lecithin } \\
\text { EYP }\end{array}$ \\
\hline
\end{tabular}


Table 3 PFC nanoemulsions for ${ }^{19} \mathrm{~F} \mathrm{MRI}$

\begin{tabular}{lll}
\hline Liquid PFC & Emulsifying agent(s) & Ref. \\
\hline Perfluorooctyl bromide & Lecithin & 53 and 54 \\
(PFOB) & Lecithin + cholesterol & $55-59$ \\
& Lecithin + safflower oil + & 60 and 61 \\
& cholesterol & \\
& EYP/phospholipids & 62 and 63 \\
Perfluoro-15-crown-5- & Lecithin & $64-66$ \\
ether (PFCE) & Lecithin + safflower oil & 67 \\
& Lecithin + cholesterol & 56 and 59 \\
& Lecithin + phospholipids & 68 \\
& EYP/phospholipids & 62 and 69-72
\end{tabular}

the following reports are variations or improvements of two main formulation strategies. The first and more straightforward one was initially proposed by Ahrens and coworkers, and maximized the fluorine content of the emulsion using lecithin and safflower oil. ${ }^{67}$ A slightly more complex approach was investigated by the group of Lanza and Wickline. It focused on more flexible probes, in which the fluorinated oil core was surrounded by a multifunctional layer containing targeting ligands, drugs, dyes, etc. Typically, a surfactant-lipid comixture was the emulsifying agent. It was demonstrated that such biotinylated lipid-coated nanoemulsions of liquid PFCs in water also have interesting echogenic properties useful for combined ultrasound imaging. ${ }^{68}$ Further developments based on this strategy included the preparation of lipid-stabilized fluorocarbon nanoemulsions loaded with therapeutic drugs or aimed at the imaging of specific pathologies such as atherosclerosis or cerebral ischemia, as already described in previous reviews. ${ }^{51,74}$ Stabilizing shells based on proteins have been used also in this field. Using sonochemistry, Webb et al. developed crosslinked bovine serum albumin shells encapsulating perfluorononane droplets with a mean diameter of $2.5 \mu \mathrm{m} .^{75}$

The potential of HFBs in stabilizing liquid fluorocarbon emulsions has also been demonstrated, although no experimental reports of their use in ${ }^{19} \mathrm{~F}$ MRI imaging has yet been reported to date. HFBs were shown to be effective stabilizers for aqueous dispersions of liquid perfluorocarbons, effectively preventing droplet coalescence (Fig. 3). The hydrophobin HFBI allowed preparing $\mathrm{o} / \mathrm{w}$ emulsions of different commercially available fluorous liquids, i.e. Galden ${ }^{\mathrm{TM}}$ SV90, perfluorooctyl bromide and tris(perfluoropentylamine) (Fluorinert ${ }^{\mathrm{TM}}$ FC-70), and proof-of-concept experiments demonstrated the possibility to produce them also in microfluidic systems. ${ }^{76}$ This approach permitted a good control over droplet size and shape, and the obtained emulsions were reported to be stable for at least one month, thus indicating a potential for successful use also in the biomedical imaging field. PFC nanoemulsions effectively labelled monocytes and macrophages when injected intravenously, and provided positive signals at sites of inflammation in animal models. They were therefore naturally studied also for ${ }^{19} \mathrm{~F}$ MRI cell tracking. Up to now, the more stable PFC formulations for this purpose were prepared using lipids. ${ }^{77}$ This protocol, originally established for liquid ${ }^{19} \mathrm{~F}$ MRI tracers, has recently proved successful also for the solid
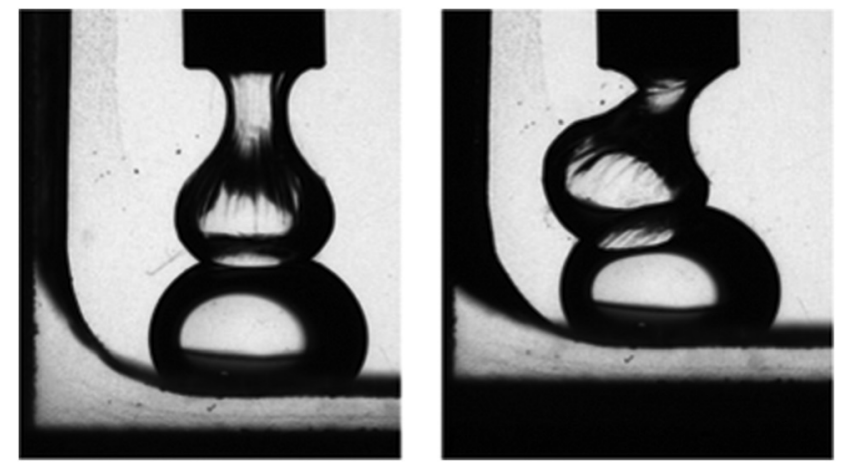

Fig. 3 Two Galden SV90 droplets in an aqueous solution of the hydrophobin HFBI cannot coalesce, due to the formation of a protein interfacial film (reproduced from ref. 76 with permission from the Royal Society of Chemistry).

superfluorinated contrast agent PERFECTA, which has been introduced as a more sustainable alternative due to its branched structure containing short perfluorocarbon segments. ${ }^{78}$ Its homogeneous emulsion in an aqueous solution containing $4 \%$ lecithin and $4 \%$ safflower oil was stable for weeks at room temperature, and suitable for in vivo cell tracking and trafficking. Stable aqueous dispersions of PERFECTA were also prepared by using HFBII as a biosurfactant. Preliminary proofs of the success of this alternative formulation protocol were given by DLS and NMR experiments. Both afforded similar results if compared to PERFECTA emulsion with lecithin and safflower oil. ${ }^{79}$

\subsection{Vesicles and liposomes for encapsulation and drug delivery}

Fluorinated vesicles were traditionally obtained from standard phospholipids and partially fluorinated alkanes, whose F-segments self-organized through their bilayers, making them thermally stable even under heat sterilizing conditions. In addition to that, the presence of strongly hydrophobic and lipophobic fluorinated chains increased their drug encapsulation ability compared to hydrogenated analogs, as confirmed by the significantly slower release of model drugs in buffer or serum. ${ }^{45}$ These features render fluorinated vesicles and liposomes highly promising platforms for biomedical applications in the field of drug encapsulation and delivery. Among the most common techniques for building capsules, the use of bubbles and emulsion drops - stabilized by surfactants, proteins or nanoparticles - as templates allows controlling the size and size distribution of the droplets. Lipid bilayers, formed by two sheets of amphiphilic phospholipids, constitute a barrier between liquid compartments in cells and are widely used for drug delivery in the form of liposomes. Similar building blocks, like amphiphilic proteins, may fulfill the same task, affording new lipid-free platforms for synthetic biology or drug delivery. In a very recent paper by Hähl et al., protein-based bilayers and vesicles containing the ion channel-forming peptide gramicidin A were prepared in water, oily media, and 


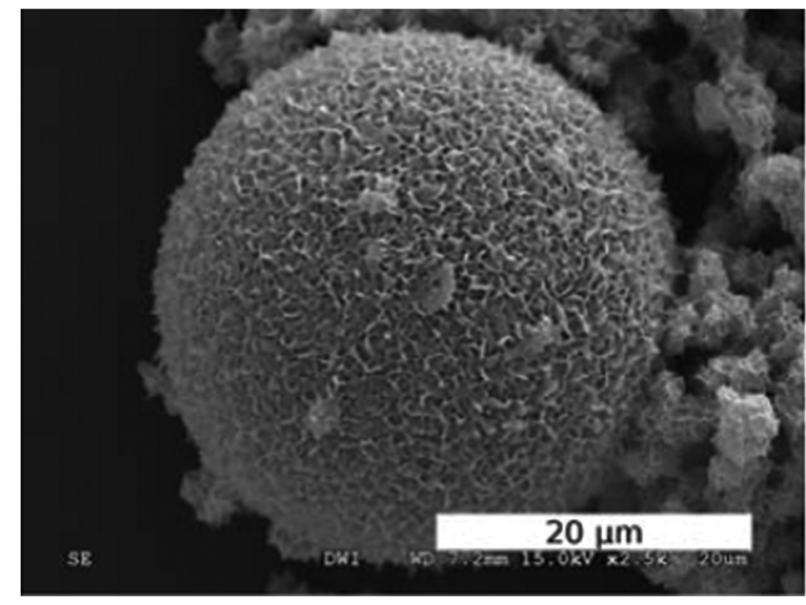

Fig. 4 Calcium phosphate capsules synthesized from an HFB-stabilized perfluorooctane/water emulsion remained intact even after 68 days of mineralization (reproduced from ref. 81 with permission from the Royal Society of Chemistry).

even in air, using native HFBI and the microfluidic jetting technique. Among the selected hydrophobic phases, the fluorinated oil Fluorinert ${ }^{\mathrm{TM}}$ FC-70 was also successfully employed. ${ }^{80}$ Schulz et al. used HFB-stabilized perfluorooctane/water emulsions as templates for the growth of mineral shells. They reported a straightforward water-based synthesis of hybrid capsules composed of HFB and hydroxyapatite (Fig. 4). ${ }^{81}$

Being permeable for small molecules, these mineral shells may find useful applications as microreactors or for food, cosmetics, and drug delivery. Furthermore, calcium phosphate is naturally present in the bones and teeth of living organisms, and thus their decomposition products are likely to be biocompatible and may be exploited for the deposition of useful minerals.

HFBs have also been employed to stabilize aqueous dispersions of supraparticles composed of gold nanoparticles with hydrophobic dodecylthiol shells. ${ }^{82}$ Such supraparticles could effectively encapsulate hydrophobic drugs and release them upon reduction of the protein film by glutathione. Recent research proved that this same approach is valid also for nanoparticles featuring fluorinated shells instead of simple hydrocarbon ones. $^{83}$

\section{Coating and modification of fluorinated solid surfaces}

\subsection{Surface coating and functionalization}

Modifying low energy, highly hydrophobic solid surfaces to make them wettable by polar liquids such as water is a challenging task. Surface-active agents are an effective way to improve the wetting properties of this type of solid substrates, which in many cases consist of partially or fully fluorinated polymers, e.g. polytetrafluoroethylene (PTFE). Although synthetic surfactants are still mostly used for this purpose, it has been demon- strated that naturally occurring amphiphiles can also adsorb efficiently on these surfaces and modify their wetting properties, or even act as intermediates for further functionalization. Lecithin is a complex mixture of neutral lipids (mainly triacylglycerols), polar lipids (phospholipids and glycolipids) and carbohydrates. After the formation of phospholipid micelles in hexane-oil mixtures, the adsorption of pure lecithin phospholipids (Chart 2) and soybean oil was shown to be more effective onto hydrophobic surfaces with a water contact angle $>50^{\circ}$ (including PTFE), compared to hydrophilic ones. ${ }^{84}$ This finding is particularly significant for the food industry, which mostly uses soybean lecithin as an emulsifier. Soybean lecithin contains phosphatidylcholine, phosphatidylethanolamine, phosphatidylinositol, and phosphatidic acid, together with a relatively large amount of triglycerides. Removal of these phospholipids from soybean oil (a process called 'degumming') can be achieved by means of polymeric membranes; however chemical interaction between membrane surfaces and bulk species may cause membrane fouling and thus needs to be controlled. ${ }^{85}$ Conditioning of PTFE with the three lipopeptides, fengycin, iturin A, and surfactin, was tested by Shakerifard and coworkers, who reported a reduction of the surface hydrophobicity. ${ }^{86}$ The lowest water contact angle value of $58^{\circ}$ was reached after incubation with $0.1 \mathrm{mg} \mathrm{mL}^{-1}$ iturin A, while for the other two lipopeptides only slight reductions were noticed even at high surfactant concentrations.

Mixed surfactant systems often show better performance compared to single amphiphiles, not just in terms of improved interfacial behaviour. Mixing a synthetic surfactant with a natural one is a smart strategy to reduce the consumption and the environmental impact of the former; at the same time, it can enhance the efficiency and cost effectiveness of the latter. Plant surfactants in particular can be viewed as more advantageous than microorganism-based ones, because of more economically viable large-scale production. In this regard, a recent work by Biswal and Paria reported the mixing in different ratios of a double-chain cationic synthetic surfactant (di-dodecyldimethyl ammonium bromide, DDAB) and a plantderived surfactant, i.e. Shikakai from Acacia concinna. ${ }^{87}$ The interfacial and wetting behaviour of these mixtures on PTFE surfaces were studied by surface tension and dynamic contact angle measurements. Pure Shikakai and DDAB solutions had

a

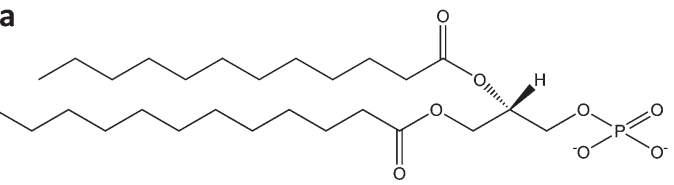

b

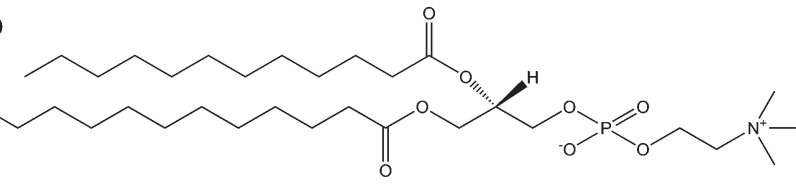

Chart 2 Chemical structures of (a) phosphatidic acid and (b) phosphatidylcholine. 
minimum contact angle values of $c a .98^{\circ}$ and $80^{\circ}$ on PTFE. Addition of DDAB to Shikakai gradually lowered the CMC, surface tension and contact angle values at the CMC. When $50 \%$ DDAB was added, the contact angle decreased by $c a .16^{\circ}$, confirming the presence of a strong synergistic interaction between the head group of DDAB and the carboxyl group of Shikakai. The same authors later reported a comparative study of adsorption kinetics and wetting behaviours of three different plant-derived surfactants (Reetha, Shikakai, and Acacia, Chart 3) on PTFE surfaces. ${ }^{88}$ In all cases, adsorption equilibrium was reached after only 15 minutes. Shikakai solutions yielded a higher surface adsorption and lower contact angle (98 $)$ than Reetha and Acacia (ca. 109 $)$. Lower adsorption densities were found at the PTFE-water interface compared to the air-water interface, and the performance was generally lower than that displayed by conventional synthetic surfactants; however, mixed co-surfactant systems might represent a viable option as described above.

The adsorption of proteins on fluoropolymer surfaces is likely to result in denaturation, as shown by Bekos et al. for BSA on poly(tetrafluoroethylene-co-hexafluoropropylene). ${ }^{89}$ This is generally not the case with HFBs, although with differences between the two classes of these proteins.

On solid surfaces, HFBs form amphipathic membranes which can turn hydrophobic surfaces into hydrophilic ones and vice versa; in several cases these films have also been exploited to allow further chemical and/or functional modification, e.g. binding of other proteins. A few studies have shown that the self-assembly ability of HFBs is maintained on solid fluorinated surfaces, despite their well-known omnirepellency. Class I HFBs are among the first proteins recognized as
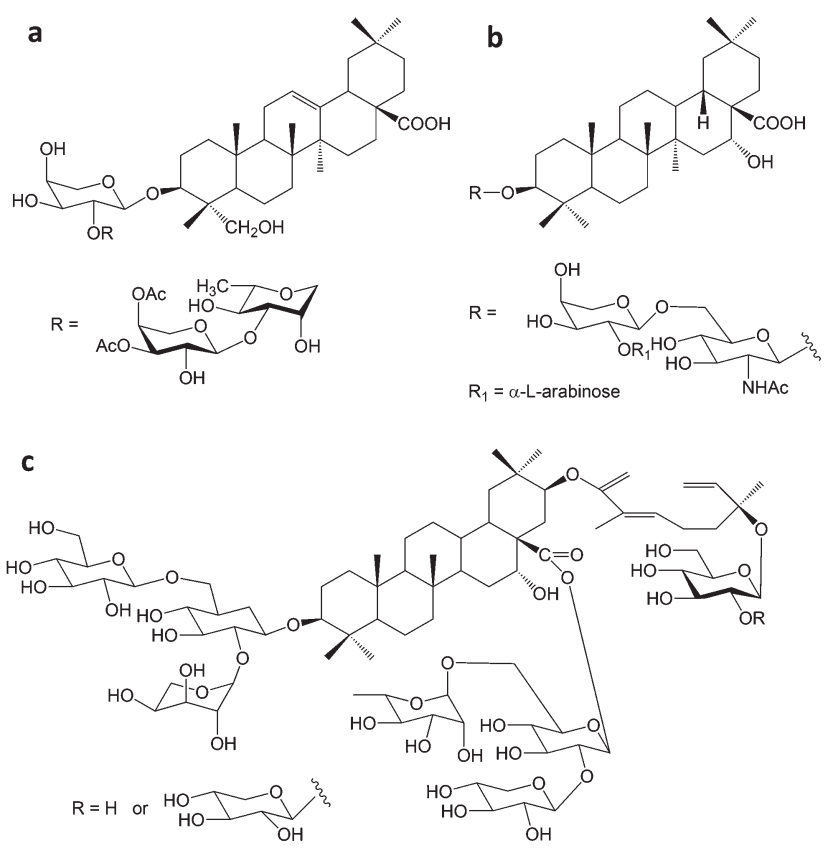

Chart 3 Chemical structures of (a) Reetha, (b) Shikakai and (c) Acacia surfactants. functional amyloids, and they form chemically strong layers on solid surfaces which can be dissolved only by strong acids. $^{90}$ After the overnight incubation of colloidal PTFE in aqueous solutions of the class I hydrophobin SC3, for example, the protein adsorbed onto the surface of polymeric nanospheres with a high-affinity adsorption isotherm, reaching a plateau value of $1.5 \mathrm{mg} \mathrm{m}^{-2}$ and lowering the water contact angle of PTFE sheets from $110^{\circ}$ to $48^{\circ}$ or $66^{\circ}$, depending on the glycosylation state of the protein. ${ }^{91}$ Treatment with detergents at high temperature induced a structural transition from an $\alpha$-helical to a $\beta$-sheet state, and the protein film could not be removed even by washing at $100{ }^{\circ} \mathrm{C}$ with $2 \%$ sodium dodecyl sulfate. ${ }^{92}$ Recently it has been proposed to exploit this behaviour for the isolation and purification of class I HFBs in a solid phase extraction process based on adsorption on PTFE microparticles, followed by harsh elution conditions. ${ }^{93}$ Class II HFBs were reported to undergo only very small conformational changes upon assembly at aqueous-fluorous interfaces. ${ }^{94}$ On solid fluoropolymer surfaces, HFBI and HFBII form less stable interfacial membranes which can be removed by treatment with detergents but assemble more quickly than those of class I HFBs, requiring minutes rather than hours. These HFBs are still rather efficient in changing the wettability of fluoropolymer surfaces, and lower the water contact angle of PTFE down to the $50-60^{\circ}$ range. $^{95,96}$ In a somewhat reversed approach it may be desirable to introduce fluorocarbon moieties on the surfaces of other materials such as non-fluorinated polymers, in order to improve their performance in terms of e.g. chemical resistance, friction reduction and barrier properties, or to control their wettability features. Adhesion issues can be encountered if simple physical deposition is used, and more stable modifications may require energy-intensive or environmentally unfriendly activation procedures for substrates with low chemical reactivity. Using HFBII as a primer layer, poorly reactive hydrophobic polymers (i.e. polystyrene, polypropylene, low-density polyethylene) could be rapidly and spontaneously functionalized with the phosphate-terminated perfluoropolyether Fluorolink ${ }^{\circledR}$ F10, in aqueous solutions and at room temperature. ${ }^{97}$ The presence of an HFBII monolayer on a polystyrene surface increased the binding of Fluorolink ${ }^{\circledR}$ F10 almost twenty-fold, by exploiting electrostatic interactions between the phosphate groups of the fluorocarbon and the positively charged amino acid residues of the protein (Fig. 5).

Finally, we shall briefly mention here just few examples in which biosurfactants were used as surface-modifying agents in order to achieve the subsequent immobilization of enzymes or biomolecules. Urease was covalently immobilized on silica, tungsten, and PTFE supports by linking the enzyme through its exposed carboxylic groups to surfaces coated with aminofunctionalized phospholipids. ${ }^{98}$ Compared to analogous aminated supports without phospholipid coatings, this protocol led to higher total and active immobilized enzyme yields. Moreover, on all lipid-coated surfaces, urease exhibited excellent stability and retention of activity. The enzyme bound to lipid-coated PTFE, for example, could be boiled in water for $1 \mathrm{~h}$ with only a minimal loss of activity. In a similar but more 

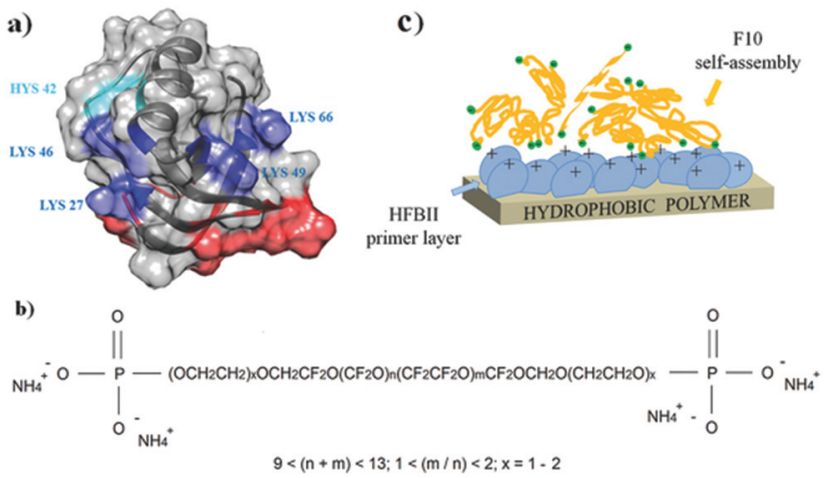

Fig. 5 Assembly of HFBII (a) and Fluorolink ${ }^{\circledR}$ F10 (b) for the surface modification of hydrophobic polymer surfaces (c), (reproduced from ref. 97 with permission from Wiley).

sophisticated approach, Chu and coworkers immobilized glucose oxidase on a PTFE membrane by using a copolymer of the phospholipid 2-methacryloyloxyethyl phosphorylcholine with 2-ethylhexylmethacrylate. The modified surfaces thus obtained were proposed for the preparation of a biosensor for the continuous monitoring of glucose. ${ }^{99}$ Ion channel proteins play a fundamental role in signal transduction phenomena, e.g. in the nervous system. Their reconstitution into artificial membranes would be greatly advantageous for the development of novel biosensors. An interesting paper from Salzer and coworkers reported the successful integration of two natural ion channel proteins, namely gramicidin A and nicotinic acetylcholine receptor, into a lipid/PTFE matrix. ${ }^{100}$ The functionality of both proteins in these artificial mimic platforms was not modified, as confirmed by single channel patch-clamp measurements.

\subsection{Biocompatible artificial surgical implants}

One special case of surface modification which deserves a separate discussion is that of artificial surgical implants, which are widely used to replace or support several body parts (e.g. bones, spinal, cardiac and dental tissues). The insufficient biocompatibility of the non-physiological materials used in these devices, however, often leads to poor integration into human tissues. Therefore engineering of their surface, physical, and mechanical properties is necessary to enhance implant performance in the biological environment.

PTFE is considered one of the most inert and oxidationresistant polymers. This feature made it widely used for the manufacture of prostheses, graft augmentation devices, and microporous hydrophobic membranes for surgical implants. Among all its possible applications in surgery, the use of PTFE vascular grafts for the treatment of leg ischaemia is frequent when endogenous saphenous veins are not available. Unfortunately, the insertion of synthetic blood conduits can induce a negative host response. In particular, lipid retention - which is a well-known cause of atherosclerosis - was often observed in arterial prostheses explanted from humans. Phospholipids are a major constituent of the whole lipid com- position of human blood, and among them, phosphatidylcholine is an important component of platelets and red blood cell membranes. Phosphatidylcholine-based lipids, combined with cholesterol, play a major role in the evolution of atherosclerosis. A study by Vermette et al. examined lipid concentration profiles across prosthesis membranes exposed to lipid dispersions under various conditions, and found that lipids first rapidly adsorbed onto PTFE surfaces due to their strong affinity for this highly hydrophobic polymer, and then filled in the prosthesis wall, until the membrane became completely impermeable to fluids. ${ }^{101}$

Another crucial issue associated with synthetic vascular implant failure is lipidic radial transport across the wall of expanded polytetrafluoroethylene (ePTFE) arterial prostheses. An in vitro model developed by the same group investigated how the radial transport of a phosphatidylcholine dispersion across the wall of an ePTFE prosthesis affected the circumferential mechanical properties of the implant itself. ${ }^{102}$ When commercial ePTFE prostheses were exposed to various transmural pressures and/or lipid concentration gradients, phospholipids gradually accumulated up to the external reinforcing wrap of the prosthesis, which acted as a rigid barrier. After lipid adsorption however the rigidity of the wrap decreased compared to the pristine prosthesis, which may lead to serious clinical implications if happening in vivo. Controlled phospholipid adsorption, however, may be turned into an advantage. In an early study, Köhler et al. covalently grafted a layer of carboxylated egg lecithin to aminated PTFE in order to prepare nonthrombogenic coatings. ${ }^{103}$ By mimicking the surface of inactive platelets and red blood cell membranes, which are biologically inert, the modified materials displayed a capability to reduce platelet adhesiveness to the surface. In a similar approach, Jordan and coworkers applied a stable membranemimetic film by immobilizing and subsequently polymerizing an acrylate-modified phospholipid on gelatin-impregnated ePTFE, using an interposed terpolymer layer to control phospholipid assembly. ${ }^{104}$ Polyurethanes (PUs) are used as coating or structural materials for most cardiovascular products, and thus need to be biocompatible and stable in vivo for a prolonged period. Unfortunately, PUs are not completely thrombo-resistant, and surface coating is required to increase their blood compatibility. The surface of a hydrophobic fluorinated polyurethane containing 2,2,3,3-tetrafluoro-1,4-butanediol chains was easily modified by the Langmuir-Blodgett method using DSPC. ${ }^{105}$ From in vitro platelet adhesion assays, FPU coated with a DSPC monolayer proved to be more plateletcompatible than the corresponding unmodified substrate. DSPC formed a cytomimetic layer, which led to a significant reduction of platelet adhesion and activation (Fig. 6).

The ability of HFBs to modify the wettability and act as functionalization intermediates of fluoropolymer surfaces can also be exploited to improve the biocompatibility of fluoropolymer implants. Scholtmeijer, Janssen and coworkers coated PTFE surfaces with engineered variants of the hydrophobin SC3 which featured a fibronectin cell-binding RGD motif and/ or the deletion of 25 amino acids at the $\mathrm{N}$ terminus of the 

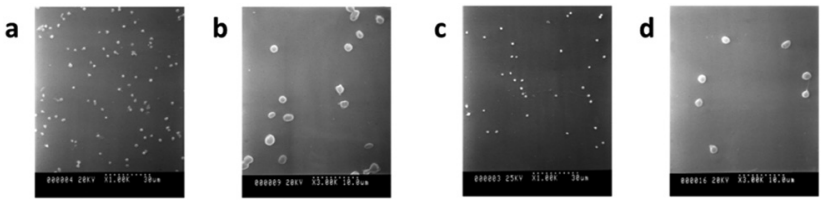

Fig. 6 SEM images of platelet adhesion on spin-coated FPU surfaces as such $(a, b)$ and modified with a DSPC monolayer ( $c$, d), (adapted from ref. 105 with permission from Taylor \& Francis).

protein, and found that both changes could lead to enhanced fibroblast growth (Fig. 7). ${ }^{106,107}$

A significant problem for many surgical and medical devices is their colonization by structured multicellular communities of bacteria (i.e. biofilms), a phenomenon that represents a continuous source of infection. Surface modification is a smart approach to retard or avoid biofilm formation. The ability of hydrophobins to form anti-biofilm coatings on PTFE surfaces has been recently reported by Artini and coworkers, who demonstrated the anti-biofilm efficiency of self-assembled amphiphilic layers formed by two fungal hydrophobins ( $\mathrm{Vmh} 2$ and Pac3) on different medically relevant materials, including PTFE disks. ${ }^{108}$ Using a CDC biofilm reactor for biofilm growth, the authors showed that both these class I HFBs are able to reduce the biofilms formed by different strains of Staphylococcus epidermidis, a significant nosocomial pathogen in indwelling medical devices.

\subsection{Colloidal dispersions of fluorinated particles}

One last particular case of surface modification which will be described separately is that of colloidal dispersions of solid fluorinated particles. In order to favour application as coatings, sealants and lubricants, fluoropolymer particles need to be dispersed in a liquid medium. Aqueous solutions represent the most inexpensive and environmentally friendly choice; however the extreme hydrophobicity of these materials makes them difficult to prepare. Uncoated PTFE particles for example do not wet-in or disperse in water even when high-energy ultrasonication is applied. Commonly available non-ionic surfac-

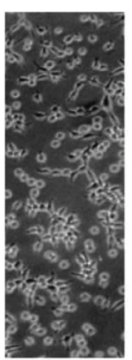

Bare Teflon

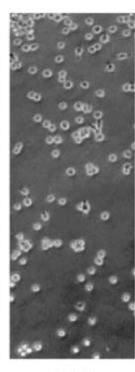

$\mathrm{SC} 3$

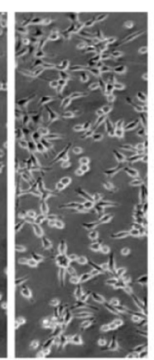

RGD-SC3

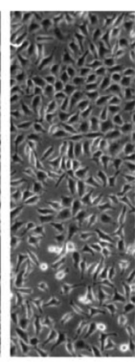

TrSC3

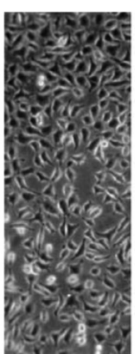

RGD-TrSC3

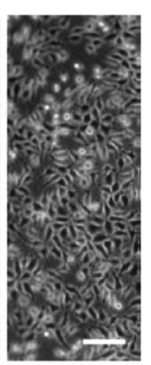

TCPS
Fig. 7 Fibroblast growth on PTFE surfaces modified with the hydrophobin SC3 fused with an RGD motif and/or featuring a 25-amino-acidstrand deletion at the $\mathrm{N}$ terminus (TrSC3). Cells grown in multi-well tissue culture polystyrene plates (TCPS) are also reported as a control (reproduced from ref. 107 with permission from Elsevier).
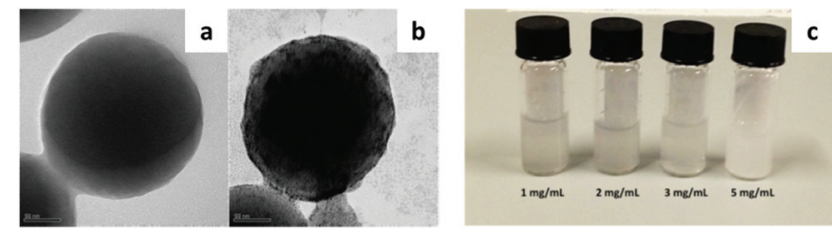

Fig. 8 TEM images of uncoated (a) and HFBll-coated (b) PVDF nanoparticles. (c) Resuspension in water of previously freeze-dried aqueous dispersions of HFBII-coated PVDF nanoparticles (adapted from ref. 109 with permission from Elsevier).

tants are effective for this purpose only if used in high concentrations, and often lead to dispersions that are not stable at high temperature or under harsh chemical conditions.

Static water contact angle measurements proved that very low concentrations of HFBs (typically $25-50 \mu \mathrm{g} \mathrm{ml}{ }^{-1}$ for SC3 and $200-220 \mu \mathrm{g} \mathrm{ml}^{-1}$ for HFBII) could facilitate the wet-in of Teflon® MP1600 and TE5069 solid particles into aqueous solutions, even though sonication was required and the particles eventually settled at the bottom of the vials. ${ }^{96}$

Poly(vinylidene fluoride) (PVDF) is another highly hydrophobic fluorinated polymer with a broad range of applications, spanning from electronic devices to membranes and nanocomposite materials. It is also widely used in coatings and paints due to its low surface energy, but poor water solubility represents a significant limitation from the applicative point of view. The first example of an environmentally friendly aqueous dispersion of partially crystalline PVDF nanoparticles was recently obtained by the use of HFBs. ${ }^{109} \mathrm{HFBI}$ and HFBII were able to reverse the surface wettability of the nanoparticles, without significantly changing their size or the polymer crystalline phase. In addition, the water dispersibility of the protein-coated particles was not affected by lyophilization, so that it was possible to freeze-dry the dispersions, store them for weeks and then redisperse them in water (Fig. 8).

\section{Summary and future outlook}

Perfluorocarbons possess a unique set of properties that make them hardly replaceable in advanced technological applications. Among these features are their extremely low surface tension and high hydrophobicity, which however constitute a significant limitation whenever the preparation of aqueous dispersions is required, e.g. for biomedical imaging or to prepare organic solvent-free products for coating applications. While synthetic surfactants based on long-chain perfluorocarbons are suitable for solving this issue from a technical performance point of view, their persistence and in certain cases their toxicity have raised concerns, such as for PFOA and PFOS. There is therefore an urgent need for replacement of these fluorosurfactants, in order to comply with higher environmental sustainability standards and with increasingly strict directives and regulations. At present, possibly the most explored alternative is the preparation of less persistent syn- 
thetic fluorosurfactants featuring shorter and/or branched perfluorinated chains, which however appear to display lower technical performance. In addition, caution has been invoked also towards these replacements, although no extensive data are yet available on their sustainability profiles. In this sense, the possibility of using naturally occurring surfactants appears as a promising alternative worth investigating. To date the largest number of studies on this topic has been reported in the biomedical field, where the expected higher biocompatibility of natural compounds clearly constitutes a further driving force for intense research, but a few examples exist also in the wider materials science field, e.g. for functional coatings or sensing applications. Phospholipids have probably received the greatest attention due to their availability in larger quantities and relative economic viability, but surface-active proteins have also been investigated. An increasing number of studies has been focusing on hydrophobins because of their exceptional surface activity and particularly because of their film-forming properties, which set them apart from other available surfactants. The main challenge in raising the technology readiness level of these applications consists in bringing hydrophobin expression and purification yields to industrially viable levels, but several efforts in this sense are ongoing. ${ }^{15}$ Besides phospholipids and hydrophobins, however, a large number of both low and high molecular weight biosurfactants exist which remain virtually unexplored in the field of fluorous chemistry, from glycolipids and lipopeptides to other surface-active proteins. ${ }^{110-113}$ For the successful replacement of synthetic fluorosurfactants with natural occurring ones, the greatest challenge consists of combining environmental sustainability with economic sustainability and with the performance requirements dictated by advanced technological applications. One possible approach consists of the use of mixtures of natural and synthetic surfactants, which can at the same time improve the effectiveness of the former while reducing the consumption and thus the overall environmental impact of the latter.

Further significant improvements may come from engineering of natural surfactants by biotechnological or chemical means, which may not only improve their performance, but also introduce entirely new functionalities. We have reviewed here a few cases taken from the biomedical field which show how this approach may lead for example to specific targeting in biomedical imaging (e.g. by modification of the lipid shell in microbubbles) or to the increased biocompatibility of surgical implants (e.g. by the introduction of fibronectin RGD motifs to the amino acid sequence of hydrophobins). Some large-scale application has already been found for denatured fluorinated whey and soy proteins in fire-fighting foams. ${ }^{114}$ A first effort has been recently made in order to increase the affinity of hydrophobins towards fluorinated phases by the addition of fluorocarbon tags, combining the film-forming properties of the proteins with the fluorophilic features and reducing the required amount of the latter. ${ }^{115}$ The introduction of new functionality through engineering means has the potential to create added value for natural surfactants, thus addressing not only the requirements in terms of environmental sustainability and technical performance, but possibly also of economic viability.

\section{Conflicts of interest}

There are no conflicts to declare.

\section{Acknowledgements}

P. M. acknowledges funding from the European Research Council (ERC) for granting the project FOLDHALO (grant no. 307108). R. M. gratefully acknowledges funding from the Academy of Finland (Project SelfSmart, decision 276537).

\section{Notes and references}

1 Global Industry Council for FluoroTechnology, https:// fluorocouncil.com (accessed September 2017).

2 A. Harsanyi and G. Sandford, Green Chem., 2015, 17, 2081.

3 J. G. Drobny, Polym. Adv. Technol., 2007, 18, 117.

4 J. G. Riess, Curr. Opin. Colloid Interface Sci., 2009, 14, 294.

5 M. P. Krafft and J. G. Riess, Curr. Opin. Colloid Interface Sci., 2015, 20, 192.

6 A. Blum, S. A. Balan, M. Scheringer, X. Trier, G. Goldenman, I. T. Cousins, M. Diamond, T. Fletcher, C. Higgins, A. E. Lindeman, G. Peaslee, P. de Voogt, Z. Wang and R. Weber, Environ. Health Perspect., 2015, 123, A107.

7 United Nations Environment Programme, Stockholm Convention, http://chm.pops.int/TheConvention/ThePOPs/ TheNewPOPs/tabid/2511/Default.aspx (accessed September 2017).

8 United States Environmental Protection Agency (EPA), https://www.epa.gov/assessing-and-managing-chemicalsunder-tsca (accessed September 2017).

9 J. S. Bowman, Environ. Health Perspect., 2015, 123, A112.

10 United Nations Framework Convention on Climate Change, http://unfccc.int/ghg_data/items/3825.php (accessed November 2017).

11 Z. Wang, I. T. Cousins, M. Scheringer and K. Hungerbuehler, Environ. Int., 2015, 75, 172.

12 S. De, S. Malik, A. Ghosh, R. Saha and B. Saha, RSC Adv., 2015, 5, 65757.

13 D. J. McClements and C. E. Gumus, Adv. Colloid Interface Sci., 2016, 234, 3.

14 J. Wang, M. Sánchez-Roselló, J. L. Aceña, C. del Pozo, A. E. Sorochinsky, S. Fustero, V. A. Soloshonok and H. Liu, Chem. Rev., 2014, 114, 2432.

15 M. Khalesi, K. Gebruers and G. Derdelinckx, Protein J., 2015, 34, 243.

16 M. B. Linder, Curr. Opin. Colloid Interface Sci., 2009, 14, 356. 
17 H. A. B. Wösten and K. Scholtmeijer, Appl. Microbiol. Biotechnol., 2015, 99, 1587.

18 M. Blesic, V. Dichiarante, R. Milani, M. Linder and P. Metrangolo, Pure Appl. Chem., 2017, DOI: 10.1515/pac2017-0703.

19 Q. Ren, A. H. Kwan and M. Sunde, Pept. Sci., 2013, 100, 601.

20 M. S. Grunér, A. Paananen, G. R. Szilvay and M. B. Linder, Colloids Surf., B, 2017, 155, 111.

21 A. Cooper and M. W. Kennedy, Biophys. Chem., 2010, 151, 96.

22 E. Unger, T. Porter, J. Lindner and P. Grayburn, Adv. Drug Delivery Rev., 2014, 72, 110.

23 R. Senior, H. Becher, M. Monaghan, L. Agati, J. Zamorano, J. L. Vanoverschelde and P. Nihoyannopoulos, Eur. J. Echocardiogr., 2009, 10, 194.

24 S. Sirsi and M. Borden, Bubble Sci. Eng. Technol., 2009, 1, 3.

25 F. Cavalieri, M. Ashokkumar, F. Grieser and F. Caruso, Langmuir, 2008, 24, 10078.

26 G. Korpanty, P. A. Grayburn, R. V. Shohet and R. A. Brekken, Ultrasound Med. Biol., 2005, 31, 1279.

27 GE Healthcare, http://www.optisonimaging.com (accessed September 2017).

28 Lantheus Medical Imaging, http://www.definityimaging. com (accessed September 2017).

29 M. Schneider, Eur. Radiol., 1999, 9, S347.

30 P. C. Sontum, Ultrasound Med. Biol., 2008, 34, 824.

31 G. Seidel, K. Meyer, C. Algermissen and A. Broillet, Ultrasound Med. Biol., 2001, 27, 915.

32 S. Pochon, I. Tardy, P. Bussat, T. Bettinger, J. Brochot, M. von Wronski, L. Passantino and M. Schneider, Invest. Radiol., 2010, 45, 89.

33 M. P. Krafft, J. Fluorine Chem., 2015, 177, 19 and references therein.

34 P. N. Nguyen, T. T. Trinh Dang, G. Waton, T. Vandamme and M. P. Krafft, ChemPhysChem, 2011, 12, 2646.

35 L. Gazzera, R. Milani, L. Pirrie, M. Schmutz, C. Blanck, G. Resnati, P. Metrangolo and M. P. Krafft, Angew. Chem., Int. Ed., 2016, 55, 10263.

36 N. Güvener, L. Appold, F. de Lorenzi, S. K. Golombek, L. Y. Rizzo, T. Lammers and F. Kiessling, Methods, 2017, 130, 4 .

37 T. Yin, P. Wang, R. Zheng, B. Zheng, D. Cheng, X. Zhang and X. Shuai, Int. J. Nanomed., 2012, 7, 895.

38 T. R. Porter, C. Arena, S. Sayyed, J. Lof, R. R. High, F. Xie and P. A. Dayton, Circ. Cardiovasc. Imaging, 2016, 9, e003770.

39 P. S. Sheeran, S. H. Luois, L. B. Mullin, T. O. Matsunaga and P. A. Dayton, Biomaterials, 2012, 33, 3262.

40 S. Lin, G. Zhang, C. H. Leow and M.-X. Tang, Phys. Med. Biol., 2017, 62, 6884.

41 J. VanOsdol, K. Ektate, S. Ramasamy, D. Maples, W. Collins, J. Malayer and A. Ranjan, J. Controlled Release, 2017, 247, 55 .
42 M. A. Kandadai, P. Mukherjee, H. Shekhar, G. J. Shaw, I. Papautsky and C. K. Holland, Biomed. Microdevices, 2016, 18, 48.

43 J. G. Riess, Chem. Rev., 2001, 101, 2797 and references therein.

44 C. I. Castro and J. C. Briceno, Artif. Organs, 2010, 34, 622.

45 M. P. Krafft, Adv. Drug Delivery Rev., 2001, 47, 209.

46 K. C. Lowe, Blood Rev., 1999, 13, 171.

47 H. A. Sloviter and T. Kamimoto, Nature, 1967, 216, 458.

48 J. G. Weers, R. A. Arlauskas, T. E. Tarara and T. J. Pelura, Langmuir, 2004, 20, 7430.

49 J. G. Riess, J. Fluorine Chem., 2002, 114, 119.

50 D. Cosco, E. Fattal, M. Fresta and N. Tsapis, J. Fluorine Chem., 2015, 171, 18.

51 I. Tirotta, V. Dichiarante, C. Pigliacelli, G. Cavallo, G. Terraneo, F. Baldelli Bombelli, P. Metrangolo and G. Resnati, Chem. Rev., 2015, 115, 1106.

52 Y. Singh, J. G. Meher, K. Raval, F. A. Khan, M. Chaurasia, N. K. Jain and M. K. Chourasia, J. Controlled Release, 2017, $252,28$.

53 T. Cyrus, D. R. Abendschein, S. D. Caruthers, T. D. Harris, V. Glattauer, J. A. Werkmeister, J. A. M. Ramshaw, S. A. Wickline and G. M. Lanza, J. Cardiovasc. Magn. Reson., 2006, 8, 535.

54 A. H. Schmieder, K. Wang, H. Zhang, A. Senpan, D. Pan, J. Keupp, S. D. Caruthers, S. A. Wickline, B. Shen, E. M. Wagner and G. M. Lanza, Angiogenesis, 2014, 17, 51.

55 G. M. Lanza, X. Yu, P. M. Winter, D. R. Abendschein, K. K. Karukstis, M. J. Scott, L. K. Chinen, R. W. Fuhrhop, D. E. Scherrer and S. A. Wickline, Circulation, 2002, 106, 2842.

56 S. D. Caruthers, A. M. Neubauer, F. D. Hockett, R. Lamerichs, P. M. Winter, M. J. Scott, P. J. Gaffney, S. A. Wickline and G. M. Lanza, Invest. Radiol., 2006, 41, 305.

57 A. H. Schmieder, S. D. Caruthers, H. Zhang, T. A. Williams, J. D. Robertson, S. A. Wickline and G. M. Lanza, FASEB J., 2008, 22, 4179.

58 P. M. Winter, S. D. Caruthers, A. Kassner, T. D. Harris, L. K. Chinen, J. S. Allen, E. K. Lacy, H. Zhang, D. Robertson, S. A. Wickline and G. M. Lanza, Cancer Res., 2003, 63, 5838.

59 Y. T. Lim, Y. W. Noh, J. H. Cho, J. H. Han, B. S. Choi, J. Kwon, K. S. Hong, A. Gokarna, Y. H. Cho and B. H. Chung, J. Am. Chem. Soc., 2009, 131, 17145.

60 K. C. Partlow, J. Chen, J. A. Brant, A. M. Neubauer, T. E. Meyerrose, M. H. Creer, J. A. Nolta, S. D. Caruthers, G. M. Lanza and S. A. Wickline, FASEB J., 2007, 21, 1647.

61 A. M. Morawski, P. M. Winter, X. Yu, R. W. Fuhrhop, M. J. Scott, F. Hockett, J. D. Robertson, P. J. Gaffney, G. M. Lanza and S. A. Wickline, Magn. Reson. Med., 2004, $52,1255$.

62 C. Jacoby, S. Temme, F. Mayenfels, N. Benoit, M. P. Krafft, R. Schubert, J. Schrader and U. Flögel, NMR Biomed., 2014, 27, 261. 
63 C. Giraudeau, F. Geffroy, S. Mériaux, F. Boumezbeur, P. Robert, M. Port, C. Robic, D. Le Bihan, F. Lethimonnier and J. Valette, Angiogenesis, 2013, 16, 171.

64 J. A. McNab, A. C. Yung and P. Kozlowski, MAGMA, 2004, 17, 288.

65 U. Flögel, Z. Ding, H. Hardung, S. Jander, G. Reichmann, C. Jacoby, R. Schubert and J. Schrader, Circulation, 2008, 118, 140.

66 B. Ebner, P. Behm, C. Jacoby, S. Burghoff, B. A. French, J. Schrader and U. Flögel, Imaging, 2010, 3, 202.

67 E. T. Ahrens, R. Flores, H. Xu and P. A. Morel, Nat. Biotechnol., 2005, 23, 983.

68 A. M. Neubauer, J. Myerson, S. D. Caruthers, F. D. Hockett, P. M. Winter, J. Chen, P. J. Gaffney, J. D. Robertson, G. M. Lanza and S. A. Wickline, Magn. Reson. Med., 2008, 60, 1066.

69 E. A. Waters, J. Chen, J. S. Allen, H. Zhang, G. M. Lanza and S. A. Wickline, J. Cardiovasc. Magn. Reson., 2008, 10, 43.

70 H. Matsushita, S. Mizukami, F. Sugihara, Y. Nakanishi, Y. Yoshioka and K. Kikuchi, Angew. Chem., Int. Ed., 2014, 53, 1008.

71 M. B. Kok, A. de Vries, D. Abdurrachim, J. J. Prompers, H. Grüll, K. Nicolay and G. J. Strijkers, Contrast Media Mol. Imaging, 2010, 6, 19.

72 S. Baldus, C. Heeschen, T. Meinertz, A. M. Zeiher, J. P. Eiserich, T. Münzel, M. L. Simoons and C. W. Hamm, Circulation, 2003, 108, 1440.

73 S. S. Habif, P. E. Normand, C. B. Oleksiak and H. L. Rosano, Biotechnol. Prog., 1992, 8, 454.

74 R. Díaz-López, N. Tsapis and E. Fattal, Pharm. Res., 2010, 27, 1 and references therein.

75 A. G. Webb, M. Wong, K. J. Kolbeck, R. Magin and K. S. Suslick, J. Magn. Reson. Imaging, 1996, 6, 675.

76 R. Milani, E. Monogioudi, M. Baldrighi, G. Cavallo, V. Arima, L. Marra, A. Zizzari, R. Rinaldi, M. Linder, G. Resnati and P. Metrangolo, Soft Matter, 2013, 9, 6505.

77 J. M. Janjic and E. T. Ahrens, Wiley Interdiscip. Rev. Nanomed. Nanobiotechnol., 2009, 1, 492.

78 I. Tirotta, A. Mastropietro, C. Cordiglieri, L. Gazzera, F. Baggi, G. Baselli, M. G. Bruzzone, I. Zucca, G. Cavallo, G. Terraneo, F. Baldelli Bombelli, P. Metrangolo and G. Resnati, J. Am. Chem. Soc., 2014, 136, 8524.

79 J. Repossi, Protein stabilized nanoformulation of a superfluorinated 19F-MRI contrast agent, Master thesis, Politecnico di Milano, Italy, December 2016.

80 H. Hähl, J. Nabor Vargas, A. Griffo, P. Laaksonen, G. Szilvay, M. Lienemann, K. Jacobs, R. Seeman and J. B. Fleury, Adv. Mater., 2017, 29, 1602888.

81 A. Schulz, B. M. Liebeck, D. John, A. Heiss, T. Subkowski and A. Böker, J. Mater. Chem., 2011, 21, 9731.

82 D. Maiolo, C. Pigliacelli, P. Sánchez Moreno, M. B. Violatto, L. Talamini, I. Tirotta, R. Piccirillo, M. Zucchetti, L. Morosi, R. Frapolli, G. Candiani, P. Bigini, P. Metrangolo and F. Baldelli Bombelli, ACS Nano, 2017, 11, 9413.
83 C. Pigliacelli, D. Maiolo, Nonappa, J. S. Haataja, H. Amenitsch, C. Michelet, P. Sánchez Moreno, I. Tirotta, P. Metrangolo and F. Baldelli Bombelli, Angew. Chem., Int. Ed., 2017, 56, DOI: 10.1002/anie.201710230.

84 M. Hancer, A. Patist, R. T. Kean and H. S. Muralidhara, Colloids Surf., A, 2002, 204, 31.

85 C. Pagliero, M. Mattea, N. Ochoa and J. Marchese, J. Food Eng., 2007, 78, 194.

86 P. Shakerifard, F. Gancel, P. Jacques and C. Faille, Biofouling, 2009, 25, 533.

87 N. R. Biswal and S. Paria, RSC Adv., 2014, 4, 9182.

88 S. Paria, N. R. Biswal and R. G. Chaudhuri, AIChE J., 2015, 61, 655.

89 E. J. Bekos, J. P. Ranieri, P. Aebischer, J. A. Gardella and F. V. Bright, Langmuir, 1995, 11, 984.

90 A. Piscitelli, P. Cicatiello, A. M. Gravagnuolo, I. Sorrentino, C. Pezzella and P. Giardina, Biomolecules, 2017, 7, 45.

91 M. L. de Vocht, K. Scholtmeijer, E. W. van der Vegte, O. M. H. de Vries, N. Sonveaux, H. A. B. Wösten, J.-M. Ruysschaert, G. Hadziioannou, J. G. H. Wessels and G. T. Robillard, Biophys. J., 1998, 74, 2059.

92 X. Wang, H. P. Permentier, R. Rink, J. A. W. Kruijtzer, R. M. J. Liskamp, H. A. B. Wösten, B. Poolman and G. T. Robillard, Biophys. J., 2004, 87, 1919.

93 R. Kupcik, M. Zelena, P. Rehulka, Z. Bilkova and L. Ceslova, J. Sep. Sci., 2016, 39, 717.

94 G. Raffaini, R. Milani, F. Ganazzoli, G. Resnati and P. Metrangolo, J. Mol. Graphics Modell., 2016, 63, 8.

95 S. Askolin, M. Linder, K. Scholtmeijer, M. Tenkanen, M. Penttilä, M. L. de Vocht and H. A. B. Wösten, Biomacromolecules, 2006, 7, 1295.

96 S. O. Lumsdon, J. Green and B. Stieglitz, Colloids Surf., B, 2005, 44, 172.

97 L. Gazzera, C. Corti, L. Pirrie, A. Paananen, A. Monfredini, G. Cavallo, S. Bettini, G. Giancane, L. Valli, M. B. Linder, G. Resnati, R. Milani and P. Metrangolo, Adv. Mater. Interfaces, 2015, 2, 1500170.

98 K. M. R. Kallury, W. E. Lee and M. Thompson, Anal. Chem., 1993, 65, 2459.

99 M. Chu, H. Kudo, T. Shirai, K. Miyajima, H. Saito, N. Morimoto, K. Yano, Y. Iwasaki, K. Akiyoshi and K. Mitsubayashi, Biomed. Microdevices, 2009, 11, 837.

100 R. Salzer, J. Li, C. Rautenberg, S. Friedrich and W. D. Habicher, Macromol. Symp., 2001, 164, 239.

101 P. Vermette, J. Thibault, S. Lévesque and G. Laroche, J. Biomed. Mater. Res., Part A, 1999, 48, 660.

102 D. Mantovani, P. Vermette, M. Fiset, R. Giudoin and G. Laroche, Artif. Organs, 2000, 24, 334.

103 A. S. Köhler, P. J. Parks, D. L. Mooradian, G. H. R. Rao and L. T. Furcht, J. Biomed. Mater. Res., 1996, 32, 237.

104 S. W. Jordan, K. M. Faucher, J. M. Caves, R. P. Apkarian, S. R. Rele, X. L. Sun, S. R. Hanson and E. L. Chaikof, Biomaterials, 2006, 27, 3473.

105 L. F. Wang, Y. H. Wei, K. Y. Chen, J. C. Lin and J. F. Kuo, J. Biomater. Sci., Polym. Ed., 2004, 15, 957. 
106 K. Scholtmeijer, M. I. Janssen, B. Gerssen, M. L. de Vocht, B. M. van Leeuwen, T. G. van Kooten, H. A. B. Wösten and J. G. H. Wessels, Appl. Environ. Microbiol., 2002, 68, 1367.

107 M. I. Janssen, M. B. M. van Leeuwen, K. Scholtmeijer, T. G. van Kooten, L. Dijkhuizen and H. A. B. Wösten, Biomaterials, 2002, 23, 4847.

108 M. Artini, P. Cicatiello, A. Ricciardelli, R. Papa, L. Selan, P. Dardano, M. Tilotta, G. Vrenna, M. L. Tutino, P. Giardina and E. Parrilli, Biofouling, 2017, 33, 601.

109 C. Pigliacelli, A. D’Elicio, R. Milani, G. Terraneo, G. Resnati, F. Baldelli Bombelli and P. Metrangolo, J. Fluorine Chem., 2015, 177, 62.
110 E. Rosenberg and E. Z. Ron, Appl. Microbiol. Biotechnol., 1999, 52, 154.

111 J. R. Lu and X. B. Zhao, Curr. Opin. Colloid Interface Sci., 2007, 12, 60.

112 K. Holmberg, Curr. Opin. Colloid Interface Sci., 2001, 6, 148.

113 A. Cooper and M. W. Kennedy, Biophys. Chem., 2010, 151, 96.

114 S. Perkowitz, Universal Foam, Walker \& Co., New York, 2000.

115 R. Milani, L. Pirrie, L. Gazzera, A. Paananen, M. Baldrighi, E. Monogioudi, G. Cavallo, M. Linder, G. Resnati and P. Metrangolo, J. Colloid Interface Sci., 2015, 448, 140. 